\title{
May-Thurner syndrome presenting with deep vein thrombosis in a 42-old female
}

\author{
Mateja Sabol Pušić*1, \\ Branko Ostrički', \\ Andrej Pal' \\ Vinko Vidjak ${ }^{3}$ \\ 'County Hospital Čakovec, \\ Čakovec, Croatia \\ ${ }^{2}$ General Hospital Varaždin, \\ Varaždin, Croatia \\ ${ }^{3}$ Clinical Hospital Merkur, \\ Zagreb, Croatia
}

RECEIVED:

August 30, 2015 ACCEPTED:

September 17, 2015

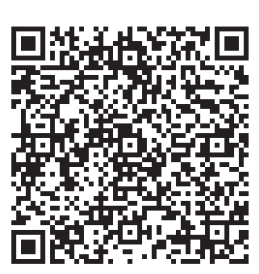

$\square$ Cardiologia Croatica 2015;10(9-10):242.
KEYWORDS: May-Thurner syndrome, combined modality therapy, thrombolysis, venous stenting CITATION: Cardiol Croat. 2015;10(9-10):242. | DOI: http://dx.doi.org/10.15836/ccar.2015.242

*ADDRESS FOR CORRESPONDENCE: Mateja Sabol Pušić, Županijska bolnica Čakovec, Ivana Gorana Kovačića 1E, HR40000 Čakovec, Croatia. / Phone: +385-98-9083512 / E-mail: matejasm@gmail.com

ORCID: Mateja Sabol Pušić, http://orcid.org/0000-0003-4895-0681 • Branko Ostrički, http://orcid.org/0000-0001-8682-5158 Andrej Pal, http://orcid.org/0000-0001-5274-7534 • Vinko Vidjak, http://orcid.org/0000-0003-3929-3130

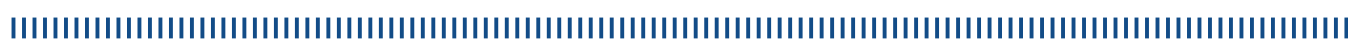

BACKGROUND: May-Thurner syndrome (MTS) is a rare cause of left iliac deep vein thrombosis (DVT) caused by an anatomical variant in which the left iliac vein is pressed against the lumbar vertebrae by the overlying right common iliac artery. According to some autopsy studies it is present in over $20 \%$ of the population, but it accounts for only 2-3\% of all lower extremity DVT and is rarely considered in differential diagnosis of DVT. Patients typically present with this syndrome in their second to fourth decade of life with sudden onset of left lower extremity edema and pain. ${ }^{1-3}$

CASE REPORT: We present a case of a female patient with no evident risk factors for thrombosis who developed extensive left iliofemoral thrombosis. Using pharmacomechanical thrombectomy followed by stent implantation and balloon angioplasty we achieved complete recanalisation of the affected veins.

CONCLUSION: In the treatment of DVT caused by May-Thurner syndrome anticoagulation can reduce thrombus propagation, but does not provide clot lysis and has no effect on post-thrombotic syndrome prevention, so it is ineffective as sole treatment. These patients are suitable for available interventional techniques which improve their outcomes and morbidity. Because of the high restenosis ratio (up to $75 \%$ ) in patients with MTS treated with thrombolysis without stent placement, it is of clinical importance to choose the appropriate treatment method to reduce short- and long-term sequelae for patients, especially post-thrombotic syndrome which represents an important medical and socioeconomic burden.

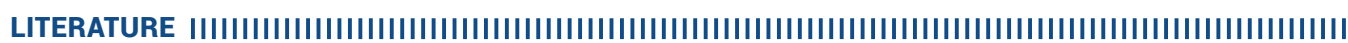

1. May R, Thurner J. The cause of the predominantly sinistral occurrence of thrombosis of the pelvic veins. Angiology 1957; 8(5):419-27. DOI: http://dx.doi.org/10.1177/000331975700800505

2. Jenkins JS, Michael P. Deep venous thrombosis: an interventionalist's approach. Ochsner J. 2014;14(4):633-40. PubMed: http://www.ncbi.nlm.nih.gov/pubmed/25598728

3. Kim JY, Choi D, Guk Ko Y, Park S, Jang Y, Lee do Y. Percutaneous treatment of deep vein thrombosis in May-Thurner syndrome. Cardiovasc Intervent Radiol. 2006;29(4):571-5. DOI: http://dx.doi.org/10.1007/s00270-004-0165-7 